\title{
Leucemia viral felina: revisão
}

\section{Maria Cecília Rodrigues Alves 1 , Laura Monteiro de Castro Conti², Paulo Sérgio Cruz de Andrade Júnior ${ }^{3}$, Dirlei Molinari Donatele ${ }^{4 *}$}

${ }^{1}$ Acadêmica do curso de Medicina Veterinária da Universidade Federal do Espírito Santo (UFES). ${ }^{2}$ Médica Veterinária autônoma. ${ }^{3}$ Médico Veterinário da Universidade Federal do Espírito Santo.

${ }^{4}$ Docente do curso de Medicina Veterinária da Universidade Federal do Espírito Santo (UFES).

*Autor para correspondência: E-mail: dirleidonatele@hotmail.com

RESUMO. A leucemia viral felina é uma doença que acomete gatos do mundo todo. $\mathrm{O}$ vírus da leucemia felina (FeLV) pode ser transmitido via saliva, pelo leite, via transplacentária ou por meio de transfusões sanguíneas. O FeLV não sobrevive em meio ambiente, e ainda pode ser facilmente eliminado por meio do uso de detergentes comuns. Uma vez infectado, o felino pode desenvolver vários sinais clínicos, os quais podem ser inespecíficos como apatia e anorexia, ou mais específicas como leucemias. $\mathrm{O}$ vírus pode gerar uma imunossupressão no animal, deixando o mesmo vulnerável a outras doenças. $\mathrm{O}$ correto diagnóstico e tratamento são essenciais para que o felino tenha uma melhor qualidade de vida, além disso, o diagnóstico de gatos infectados é um fator crucial para evitar a transmissão para um gato não infectado. Há vacinas disponíveis no mercado, mas não se sabe a duração da imunidade proporcionada por elas. Devido à importância da doença na clínica de felinos, o presente trabalho tem por objetivo apresentar uma revisão de literatura sobre a leucemia viral felina, abordando sua forma de transmissão, tratamento, epidemiologia, diagnóstico e prevenção.

Palavras chave: FeLV, diagnóstico, epidemiologia.

\section{Feline leukemie virus: Review}

ABSTRACT. The feline leukemia virus is a disease that affects cats all over the world. The feline leukemia virus (FeLV) is transmitted via the saliva, by milk, transplacental via, or through blood transfusions. The FeLV cannot survive in the environment and can be easily eliminated through the use of common disinfectants. Once infected, feline can develop many clinical signs, which may be unspecific as lethargy and anorexia or more specific as leukemias. The virus can still develop animal immunosuppression, leaving it vulnerable to other diseases. Proper diagnosis and treatment are essential to cat's better quality of life. In addition, the diagnosis of infected cats is crucial to avoid transmission to an uninfected cat. There are vaccines against FeLV available in the market; however it's unknown the duration of immunity provided by them. Due to this disease importance in feline internal medicine, this study aims to present a literature review of feline leukemia virus, with his transmission way, treatment, epidemiology, diagnosis and prevention.

Key-words: FeLV, diagnosis, epidemiology.

\section{Introdução}

A leucemia viral felina é uma doença infecciosa comum entre os gatos, causada pelo vírus da leucemia felina (FeLV), o qual foi descrito pela primeira vez em 1964, por William
Jarret e colaboradores, quando partículas semelhantes a vírus foram encontradas, ao observar em microscópio eletrônico, células retiradas de um nódulo mesentérico em gato com linfoma (Jarrett et al., 1964). 
O FeLV pertence à família Retroviridae, subfamília Oncoviridae, e gênero Gamma retrovirus. Possui como material genético RNA de fita simples, o qual é transcrito em provírus (DNA viral) pela enzima transcriptase reversa na célula do hospedeiro e é integrado no genoma da célula infectada (Figueiredo \& Araújo Júnior, 2011).

A principal fonte de infecção desse vírus é o felino persistentemente infectado e que não apresenta sinais clínicos, o qual pode eliminar por mililitro de saliva até um milhão de partículas virais (Almeida, 2009). Dessa forma, o contato íntimo entre os gatos e o compartilhamento de bebedouros e comedouros são as principais formas de contaminação; o vírus pode ser transmitido aos filhotes via transplacentária, pelo leite e pelos cuidados da mãe. Outras formas menos comuns incluem aerossóis, urina, fezes e meio ambiente, pois o FeLV não sobrevive em tais meios. A transfusão sanguínea também pode ser um meio importante de contaminação, principalmente quando não se tem conhecimento sobre a real situação do gato doador, por isso é importante a realização de testes nesses animais antes da realização da transfusão.

Os gatos com maior risco à infecção são machos, não castrados, felinos que possuem acesso à rua, que vivem em locais com outros gatos, dos quais não se tem conhecimento se são infectados ou não, e até mesmo gatis. Um gato infectado pode viver por anos, desde que seja fornecido um suporte e tratamento adequado ao mesmo, mas para isso deve-se ter conhecimento da situação do animal: se é positivo ou não para o FeLV. Por isso o diagnóstico correto é um dos fatores cruciais nessa doença.

Dentre as doenças infecciosas dos felinos, a leucemia viral felina está entre as mais importantes. Por isso, é importante realizar o diagnóstico correto das infecções por retrovírus para os animais infectados e também para aqueles não infectados, visto que uma falha no diagnóstico de um gato infectado pelo vírus pode levar à disseminação da doença para animais sadios (Levy et al., 2008). Dentre os meios de diagnóstico, o que tem sido mais utilizado é o Enzyme Linked Immuno Sorbent Assay (ELISA) por meio de kits comerciais. Esses testes fornecem um diagnóstico mais rápido, por isso têm sido muito praticado nas clínicas veterinárias. O seu diagnóstico é por meio da detecção do antígeno p27 em plasma ou, principalmente, pelo soro de gatos infectados. Outros materiais que podem ser usados para o diagnóstico são secreções nasais ou orais, mas esses meios não são uma fonte confiável, pois seus resultados não são muito precisos.

Uma vez exposto ao vírus, o felino pode apresentar infecções regressivas ou progressivas, e o que pode influenciar nesse desfecho é a resposta imune do animal, a cepa viral a que ele foi exposto, a idade do gato, o tempo dessa exposição e o estado de saúde desse felino. Uma vez infectado, o animal pode apresentar inúmeros sinais clínicos, desde sinais mais inespecíficos (como apatia, febre, vômitos) até leucemia, anemia arregenerativa, supressão da medula óssea, tumores, dentre outros. Além disso, pode fazer com que o gato fique imunossuprimido e, portanto, suscetível à infecções secundárias.

Devido à importância da doença na clínica de felinos, o presente trabalho tem por objetivo apresentar uma revisão de literatura sobre a leucemia viral felina, abordando a epidemiologia da doença, sua forma de transmissão, patogenia, diagnóstico, tratamento e prevenção.

\section{O Vírus da leucemia felina}

$\mathrm{O}$ vírus da leucemia felina pertence à família Retroviridae, e subfamília Oncoviridae. Trata-se de um vírus envelopado, possui RNA de fita simples, a partir do qual é feita uma cópia de DNA (provírus), por meio da enzima transcriptase reversa, no citoplasma da célula infectada do hospedeiro. Essa cópia de DNA viral é inserida no genoma do hospedeiro, servindo então, nas divisões celulares, como molde para novas partículas virais, as quais serão liberadas através da membrana celular (Mehl, 2004, Hartmann, 2006).

Dentre os genes presentes na fita de RNA estão: o gag (group-associated antigen) o qual codifica as proteínas, como a p10, p12, p15c e a p27; o gene pol (polimerase), específico da enzima transcriptase reversa; e o gene env (envelope) que codifica os componentes do envelope viral: a glicoproteína 70 e p15e (Hartmann, 2006).

Dentre as proteínas do FeLV se destacam a 
p15e, presente no envelope; a proteína p27, presente no núcleo, encontrada no sangue periférico, saliva, lágrimas e citoplasma de células dos animais infectados, tendo a sua detecção a base da maioria dos testes para diagnóstico da doença; e a glicoproteína 70, também presente no envelope viral, a qual possui os antígenos dos subgrupos A (FeLV-A), B (FeLV-B) ou C (FeLV-C), os quais são responsáveis pela infectividade e virulência causada. Há um subgrupo T, o qual é citolítico ao linfócito $\mathrm{T}$ e causa grave imunossupressão (Hartmann, 2006).

O FeLV-A é encontrado em todos os felinos infectados, sendo o subgrupo predominante (Quinn et al., 2005). Esse subgrupo é o único que pode ser encontrado sozinho em gatos infectados, é menos patogênico comparado aos outros, porém, o único contagioso, transmitido naturalmente de gato para gato, e está associado a imunossupressão nos gatos infectados. Foram observadas replicações in vitro do FeLV-A em tecidos de humanos, de coelhos, de porcos, e de felinos (Hartmann, 2006).

Os subgrupos B e C surgem a partir de mutações ou recombinações do DNA viral do subgrupo A. E apesar de serem mais patogênicos, suas replicações são defeituosas, pois suas glicoproteínas gp70 possuem estruturas alteradas, e isso reduz a ligação às células do hospedeiro, diminuindo assim os níveis de replicação. Todo gato em seu genoma apresenta sequências incompletas de DNA pró-viral de um vírus relacionado ao FeLV, chamado de FeLV endógeno (enFeLV). Como essas sequências são incompletas, elas não são capazes de transcrever vírions. Há indícios que o subgrupo B pode surgir a partir de recombinações entre o subgrupo A e o enFeLV, e está relacionado a neoplasias hematopoiéticas, sendo associado à maioria dos gatos com linfoma tímico. O subgrupo $\mathrm{C}$ pode surgir dessa mesma maneira, ou apenas através de mutações do subgrupo A, e está associado a anemias arregenerativas no hospedeiro. Os FeLV-B e C só são encontrados em gatos infectados em associação com o A (Sparkes, 1997, Hartmann, 2006). Replicações in vitro do FeLV-B foram observadas em tecidos de cães, hamsters, porcos, humanos, gatos e vacas; e do FeLV-C em tecidos de porquinhos da índia, cães, gatos e humanos (Hartmann, 2006).
Acredita-se que o surgimento do enFeLV tenha sido há séculos atrás, em gatos que haviam ingerido ratos infectados com o Vírus da leucemia Murina (MuLV), o qual foi capaz de se incorporar ao genoma das células do gato. $\mathrm{O}$ enFeLV não é patogênico, e é herdado. Há também o chamado FeLV exógeno, o qual é patogênico e pode ser transmitido de gato para gato (transmissão horizontal), e ambos podem estar presentes nos gatos (Hartmann, 2006).

\section{Epidemiologia}

Dentre as doenças infecciosas de felinos consideradas mais importantes, estão as causadas por retrovírus. Não se sabe a prevalência exata da leucemia viral felina, pois os exames para diagnóstico da mesma não são obrigatórios, além disso, não há uma central de dados para informação dos resultados, e os testes de triagem muitas vezes não são confirmados por outros testes. Existem testes comercialmente disponíveis para o diagnóstico da doença em questão, e apesar disso, menos de um quarto dos gatos já foram testados (Levy et al., 2008).

Apesar de a leucemia viral felina ser uma das doenças infecciosas mais comuns entre os gatos, a prevalência desta vem caindo desde 1980 na América do Norte, provavelmente devido ao incentivo da realização do programa de teste e separação, além da disponibilidade de vacinas contra a doença (Hartmann, 2006, Levy et al., 2006). Mais de 18.000 gatos norte-americanos domiciliados e de vida livre foram testados com kit comercial ELISA (Enzyme Linked Immuno Sorbent Assay) de agosto a novembro de 2004 em abrigos e clínicas veterinárias, e a prevalência da infecção foi de 2,3\%, sendo os gatos domiciliados aqueles que apresentaram maior taxa de infecção, quando comparado aos gatos de abrigos. Entre felinos domiciliados sem acesso a rua e domiciliados com acesso a rua, o segundo grupo apresentou maior taxa. Entre jovens e adultos, os adultos apresentaram maior taxa; e entre castrados e não castrados, o segundo grupo teve mais resultados positivos (Levy et al., 2006).

Uma pesquisa realizada em Madri demonstrou que de um total de 295 gatos, sendo 180 sem sinais clínicos e 115 com sinais clínicos, a maioria dos animais com resultado positivo para o vírus da leucemia felina (FeLV) eram jovens 
(menores que três anos) e machos. A prevalência da doença no grupo de animais sem sinais clínicos foi de $15,6 \%$ e de $30,4 \%$ no grupo que apresentava sinais clínicos (Arjona et al., 2000).

Em um estudo realizado em Belo HorizonteBrasil, com gatos mantidos em abrigos, dos 40 felinos submetidos ao teste, 13 (32,5\%) apresentou resultado positivo para o teste PCR (Reação em Cadeia da Polimerase), sendo quatro machos e nove fêmeas (Teixeira et al., 2007). Outro experimento em Pelotas e Rio GrandeBrasil, no qual foram coletadas amostras de sangue de 120 gatos domiciliados com acesso à rua, demonstrou que $46(38,3 \%)$ desses animais apresentaram resultado positivo para o teste IFI (imunofluorescência indireta), indicando infecção persistente, sendo 27 machos e 19 fêmeas (Meinerz et al., 2010). No município do Rio de Janeiro e Baixada Fluminense-Brasil, encontrouse que dos 1.094 gatos domiciliados submetidos ao teste IFI, $126(11,5 \%)$ apresentaram resultado positivo, e desses 126 gatos infectados, 89 $(70,6 \%)$ apresentavam algum sinal clínico relacionado à doença (Almeida, 2009).

Gatos filhotes são mais suscetíveis a se tornarem persistentemente infectados, do que gatos adultos ou idosos. Uma explicação é o fato que o número de receptores celulares necessários para o FeLV infectar as células, e então iniciar a replicação, parece diminuir em felinos mais velhos. Outra possível explicação é o nível de anticorpos anti-FeLV. Um estudo mostrou que $74 \%$ dos gatos com três anos possuíam os anticorpos, e essa taxa reduzia para $55 \%$ quando se tratava de felinos entre um e dois anos e apenas $6 \%$ em filhotes menores que cinco meses. Apesar disso, ainda são os gatos adultos que apresentam as maiores taxas de infecção (Hartmann, 2006).

Felinos com acesso a rua, machos, adultos, não castrados e presença de doenças que poderiam imunossuprimir o animal, como exemplo infecção pelo Vírus da Imunodeficiência Felina (FIV), ou anemia causada pela infecção por Mycoplasma haemofelis, são os fatores de risco para a infecção (Levy et al., 2008). Enquanto, felinos castrados que só ficam dentro de casa, estão associados com menores taxas de infecção (Levy et al., 2008).

\section{Leucemia viral felina em felinos selvagens}

A ocorrência da leucemia viral felina em gatos domésticos é muito comum, mas não se pode dizer o mesmo quando se trata de felinos selvagens, já que não há muitos relatos de casos ou estudos da doença nesses animais. Em um zoológico no Colorado-Estados Unidos, foi diagnosticada a presença do vírus em um lincevermelho (Felis rufus) criado em cativeiro. Ele foi separado de sua mãe após 48 horas de nascido, e amamentado por um gato doméstico. Foi vacinado contra rinotraqueíte, panleucopenia e calicivirose. Aos dois meses de idade, época em que se diagnosticou a presença do vírus, o animal apresentou sinais como letargia, anorexia e anemia. $\mathrm{O}$ tratamento foi à base de antibióticos, interferon, e eritropoetina. Aos 11 meses de idade, o quadro piorou, e os exames laboratoriais indicaram leucopenia, neutropenia e linfopenia, além de anemia arregenerativa. Apesar do tratamento, o animal veio a óbito 3 dias após a piora do quadro clínico (Sleeman et al., 2001).

Em uma organização não governamental na Namíbia, a Cheetah Conservation Fund (CCF), na qual abrigam e reabilitam Guepardos (Acinonyx jubatus), foram diagnosticados quatro animais positivos para FeLV. Dos quais 2 haviam histórico de ter tido contato com gatos domésticos antes de serem levados para o abrigo. Dentro da organização, apesar dos animais terem sido mantidos separadamente, e água e comida não serem compartilhadas, os animais brigaram entre si. Um dos animais adoeceu 3 meses após ser levado para o abrigo e faleceu, mas por não ter sido realizada a necropsia a causa da morte não foi determinada. Quase um ano após, um segundo guepardo também adoeceu e veio a óbito (Marker et al., 2003).

Na Arábia Saudita foi realizado um estudo, com o objetivo de avaliar a presença dos vírus: FIV, FeLV, herpesvírus felino, calicivírus felino, vírus da panleucopenia felina e coronavírus felino. Para tal, foram coletadas amostras de soro de 45 gatos selvagens (Felis silvestris), 17 gatosdo-deserto (Felis margarita) e 17 gatos domésticos ferais (Felis silvestris catus). Para o diagnóstico da infecção pelo FeLV foi realizado o teste ELISA por meio de kits comerciais. Os resultados encontrados foram: positivo em $3 \%$ nos gatos selvagens, $8 \%$ nos gatos-do-deserto, e 
$0 \%$ nos gatos domésticos ferais (Ostrowski et al., 2003).

\section{Transmissão}

A principal forma de transmissão é por meio do contado com saliva e secreções nasais de gatos infectados, assim, bebedouros e comedouros servem como fonte de contaminação. Filhotes podem ser contaminados por meio dos cuidados da mãe, via transplacentária ou pelo leite (Hardy et al., 1976, Arjona et al., 2000, Mehl, 2004, Norsworthy et al., 2004, Hartmann, 2006, Chhetri et al., 2013).

Também pode ocorrer transmissão via urina, fezes, aerossóis e o meio ambiente, porém essas são fontes menos comuns de transmissão, visto que o vírus não sobrevive em tais meios. O FeLV é sensível ao meio ambiente (Norsworthy et al., 2004, Ramsey \& Tennant, 2010) e pode ser inativado por detergentes comuns, calor, álcool ou alvejante (Mehl, 2004, Hartmann, 2006, Levy et al., 2008). Sem o uso de produtos químicos, o vírus sobrevive no ambiente por apenas uma semana (Norsworthy et al., 2004).

\section{Patogenia}

Não é certeza que o simples contato com o vírus vai resultar em viremia persistente (Norsworthy et al., 2004). Após a exposição ao vírus, o que vai determinar a manutenção da doença, é a idade em que o gato foi exposto, a resposta imune do hospedeiro, a cepa viral, a quantidade do vírus e a duração da exposição, além da presença de doenças concomitantes no momento da exposição (Sparkes, 1997, Mehl, 2004, Hartmann, 2006, Norsworthy et al., 2004).

Acreditava-se que aproximadamente um terço dos gatos expostos ao vírus em questão permanecia persistentemente infectado e os outros dois terços conseguiam desenvolver uma resposta imune adequada e eram capazes de eliminar o vírus e se recuperarem (Hoover \& Mullins, 1991). Mas pesquisas utilizando a técnica da PCR conseguiram detectar provírus em monócitos e linfócitos circulantes nas primeiras duas semanas pós-infecção experimentais, mesmo quando antígenos não eram detectados; além disso, alguns animais durante todo $\mathrm{o}$ experimento apresentaram resultado negativo na detecção do antígeno p27, porém positivo no PCR. Sugerindo ser provável que os gatos permaneçam infectados durante toda a vida, visto que foi detectado provírus nesses animais, mesmo eles tendo eliminado o antígeno p27 da circulação (Hofmann-Lehmann et al., 2001).

Há vários resultados possíveis após a exposição viral. $\mathrm{O}$ animal pode desenvolver uma infecção regressiva, onde há resposta imune eficaz e ocorre a neutralização do vírus na fase inicial da infecção. Esses gatos possuem altos níveis de anticorpos anti-FeLV, tornando-se resistentes a infecções por um período indeterminado. Nesses casos o gato não apresenta viremia e nem antígenos no sangue são detectados. Isso explicaria o fato de só uma pequena parte dos gatos se tornarem virêmicos, apesar de uma proporção muito maior apresentar evidências de que foram expostos ao FeLV, por terem anticorpos contra o agente (Hartmann, 2006). Em uma infecção regressiva, o sistema imune do hospedeiro detém a replicação viral antes que a infecção atinja a medula óssea (Levy et al., 2008).

O gato pode também não conseguir ter uma resposta imune adequada, e o vírus acaba por infectar linfócitos e monócitos. Nessa fase inicial pode haver alguns sinais clínicos como febre, linfoadenomegalia e apatia. Depois de certo tempo o felino pode conseguir eliminar essa viremia antes que a infecção atinja a medula óssea, quando isso ocorre, é chamada de viremia transitória. Nesse tipo de infecção, inicialmente antígenos são detectados nos testes, mas depois, dentro de semanas a meses (no máximo 16 semanas), tais testes passam a ter resultados negativos (Hartmann, 2006).

Há relatos de pesquisas que quando o animal desenvolve infecção regressiva ou transitória, apesar de não serem detectados antígenos, a realização de PCR nesses animais, mostra que eles não eliminam de fato a infecção, pois são encontrados, ainda que em quantidades pequenas, provírus em linfócitos circulantes (Levy et al., 2008). Apesar disso, é improvável que esses felinos desenvolvam quadros clínicos causados pela doença ou secretem o vírus. E mesmo que o agente não seja secretado, animais que se enquadram nesses casos podem transmitir a doença, por meio de doação de sangue, visto que 
o provírus presente pode ser infeccioso.

Nos felinos que desenvolvem uma viremia persistente, o FeLV progride em todos os estágios da doença, atinge a medula óssea e se dissemina para o organismo (Norsworthy et al., 2004, Levy et al., 2008). Nesses casos, ocorre uma produção ineficiente de anticorpos e o animal pode acabar desenvolvendo as doenças relacionadas (Levy et al., 2008). Na viremia persistente, a infecção atinge a medula óssea dentro de quatro a seis semanas após a exposição (Sparkes, 1997).

$\mathrm{Na}$ maioria dos gatos infectados, podem ser encontrados antígenos no sangue duas a três semanas após a exposição ao agente, e duas a oito semanas mais tarde não são mais encontrados (Levy et al., 2008).

$\mathrm{O}$ vírus pode ficar em estado de latência no gato, na qual este não consegue adquirir imunidade contra o agente, mas também não se torna persistentemente virêmico. Nesses casos, o DNA viral vai estar presente no genoma do animal, porém não vai ocorrer replicação (Norsworthy et al., 2004). Nas divisões celulares, esse DNA viral também vai ser passado para as próximas células, porém não vai ser transcrito em proteínas e nenhuma partícula viral infecciosa vai ser produzida. Dessa forma, gatos que se enquadram nesse tipo de infecção não secretam o vírus e não são fontes de contaminação para outros gatos. Não há presença de antígenos virais e, portanto testes ELISA e IFI possuem resultado negativo, bem como cultura viral de amostras de sangue. Apenas o teste PCR ou cultura viral de amostras da medula óssea são positivos (Hartmann, 2006). Caso o gato, por algum motivo, fique imunossuprimido, o vírus pode tornar a se replicar e o animal pode apresentar sinais clínicos. O tempo em que um felino pode ficar nesse estado de latência varia de indivíduo para indivíduo, pode durar de semanas a meses, mas também pode ficar a vida toda nesse estado (Sparkes, 1997). À medida que o tempo passa, se torna mais difícil de ocorrer à reativação da replicação viral, e após dois anos nesse estado é considerado quase impossível que isso ocorra (Hartmann, 2006).

Pode também ocorrer uma infecção localizada, onde ocorre replicação viral localizada em alguns tecidos como em olhos, glândula mamária, bexiga, baço e linfonodos (Hayes et al., 1989, Hartmann, 2006, Levy et al., 2008, Norsworthy et al., 2004). Há uma baixa e intermitente produção de antígenos, e os resultados dos testes podem alternar entre positivo e negativo. Fêmeas portadoras imunes podem transmitir o vírus, por meio do leite para os filhotes mesmo não apresentando resultado positivo nos testes de detecção do antígeno (Hartmann, 2006, Norsworthy et al., 2004).

Por fim, há gatos que apresentam a infecção aguda, a qual resulta da exposição oronasal, seguida de replicação viral em células mononucleares (macrófagos e linfócitos) em tecidos linfóides locais. Dentro de 14 dias essas células disseminam o vírus para medula óssea e para as células do epitélio intestinal (Sparkes, 1997).

A orofaringe é o primeiro local de replicação viral, seguido de disseminação pelo organismo até a medula óssea, caso a infecção persista, o vírus é carreado pela circulação, por meio de plaquetas e neutrófilos infectados, ocorre à infecção de estruturas epiteliais, como glândulas salivares e lacrimais, com consequente eliminação de grande quantidade do vírus por meio de tais secreções (Quinn et al., 2005).

Para a produção de provírus é necessário síntese de DNA celular, por isso tecido com atividade mitótica alta, como epitélio e medula óssea, são alvos do vírus. A alta multiplicação viral nos tecidos hemolinfáticos pode levar à anemia e imunossupressão, devido à depleção de células linfóides e mielóides (Quinn et al., 2005).

Dessa forma, há seis estágios da leucemia viral felina: no primeiro estágio ocorre replicação viral local em tecidos linfóides (tonsilas e linfonodos faríngeos através da exposição oronasal); no segundo estágio ocorre infecção de macrófagos e linfócitos circulantes; no terceiro estágio ocorre replicação viral em baço, tecido linfóide associado ao intestino e linfonodos; no quarto estágio há replicação em células da medula óssea e células epiteliais das criptas intestinais; no quinto estágio há disseminação através de neutrófilos e plaquetas infectados oriundos da medula óssea, ocorrendo viremia periférica; por fim, no sexto estágio ocorre disseminação da infecção em células epiteliais e glandulares, com conseqüente secreção do vírus 
em saliva e lágrimas (Mehl, 2004). O teste ELISA no soro é negativo no primeiro estágio, assim como o PCR, e o IFI torna-se positivo apenas a partir do quarto estágio.

\section{Sinais clínicos}

Os sinais clínicos vão depender dos órgãos atingidos e do tipo de doença que o vírus vai desencadear. Eles podem ser inespecíficos (como perda de peso, depressão ou anorexia) ou específicos, causados pelo próprio vírus ou resultantes de infecções secundárias. $O$ vírus pode causar uma imunossupressão direta no animal, podendo ser responsável pelo desenvolvimento de doenças degenerativas (como anemia não regenerativa), ou doenças proliferativas (como linfomas e leucemias) (Norsworthy et al., 2004, Ramsey \& Tennant, 2010). O DNA viral pode estar inserido em vários locais no genoma do gato infectado e, portanto, influencia significativamente na regulação das células. Esse provírus pode interromper, inativar, ou até alterar expressão de genes da célula infectada, podendo levar a tumores e desordens mielossupressoras. Ainda não se sabe o exato mecanismo pelo qual o FeLV consegue provocar tantas desordens no organismo do gato infectado (Hartmann, 2006).

Em um estudo realizado em hospitais veterinários universitários na America do Norte demonstrou que dos 8.642 gatos infectados pelo FeLV, 15\% apresentavam infecções secundárias como infecções no trato respiratório superior, Mycoplasma haemofelis (M. haemofelis), Vírus da Imunodeficiência Felina (FIV) e estomatite; $11 \%$ apresentava anemia; 6\% linfoma; 5\% trombocitopenia ou leucopenia e $4 \%$ dos gatos apresentavam doenças mieloproliferativas ou leucemia (Hartmann, 2006).

O gato imunossuprimido pode desenvolver estomatite, provocada por bactérias ou calicivírus; pode apresentar diarréia ou vômito por infecções secundárias, ou devido ao desenvolvimento de enterite. Pode ter icterícia, a qual pode ser: (i) pré-hepática, devido à eritrofagocitose provocada pelo vírus ou por infecção secundária por $M$. haemofelis; (ii) hepática, devido a linfoma hepático, necrose hepática, ou lipidose; (iii) pós-hepática por linfoma alimentar.
As neoplasias mais comuns relacionadas a essa doença são o linfoma (alimentar, muitas vezes atingindo fígado, intestino delgado ou linfonodo mesentérico; mediastinal; e o multicêntrico) e a leucemia (Quin et al., 2005; Hartmann, 2006). Essas duas neoplasias representam cerca de $30 \%$ de todos os tumores de gatos. Felinos infectados pelo FeLV têm mais chances de desenvolver o linfoma que gatos não infectados. O linfoma mediastinal cresce próximo ao timo e pode resultar em efusão pleural, podendo apresentar dispnéia ou regurgitação como sinais clínicos. O linfoma alimentar pode ter como sinais clínicos a diarréia e vômito, e também perda de peso e anorexia. Aproximadamente metade dos gatos com linfoma multicêntrico possuem resultado positivo para FeLV, e qualquer órgão pode estar envolvido nesse tipo de tumor (Hartmann, 2006). Pode ocorrer linfoma renal ou glomerulonefrite, levando à falência renal e sinais como polidipsia, perda de peso, poliúria e incontinência urinária.

As leucemias mais comumente provocadas pelo vírus em questão são a linfocítica e mielogênica (Mehl, 2004; Hartmann, 2006). Na leucemia eritrocítica o número de eritrócitos nucleados é alto, pode ocorrer trombocitopenia, e até haver supressão da hematopoiese. Os sinais clínicos podem ser apatia, devido à anemia provocada; esplenomegalia e hepatomegalia com icterícia (Hartmann, 2006).

O sistema nervoso e o oftálmico também podem ser atingidos. No primeiro, devido à ocorrência de linfoma, podem ser apresentados sinais clínicos como mudanças de comportamento, ataxia, tetraparesia, paraparesia, anisocoria ou fraqueza. Linfomas oculares podem resultar em blefaroespasmo, rubor aquoso, glaucoma, miose ou luxação de lente. Infecções secundárias por Toxoplasma gondii, Vírus da Peritonite Infecciosa Felina (PIF), Cryptococcus neoformans, dentre outros agentes também podem ser os responsáveis por doenças nestes dois sistemas. Fêmeas com o FeLV podem apresentar aborto, natimortalidade, ou ainda pode ocorrer infecção dos filhotes via transplacentária, e caso essa última ocorra, geralmente esses filhotes morrem ou desenvolvem síndromes agudas.

A maior complicação não neoplásica que 
ocorre nesses gatos infectados pelo FeLV é a anemia. Há relatos de que mais de dois terços de todas as anemias arregenerativas em felinos são provocadas pelo FeLV, mas isso pode ser uma superestimação, visto que a prevalência da doença tem caído. É comum gatos infectados apresentarem desordens hematopoiéticas, principalmente citopenia, devido à supressão da medula óssea. Essa supressão pode resultar em neutropenia (a qual pode ser transitória ou persistente), panleucopenia, anormalidades plaquetárias, além de anemia (regenerativa ou arregenerativa). Além disso, o provírus integrado ao genoma do hospedeiro pode fazer com que haja a expressão de antígenos na superfície das células, provocando assim uma destruição imunomediada da mesma. $\mathrm{O}$ animal pode apresentar como sinais clínicos: apatia, mucosas pálidas, esplenomegalia, icterícia e anorexia (Hartmann, 2006).

\section{Diagnóstico}

Antes de adentrar no diagnóstico da leucemia viral felina, é importante ressaltar algumas questões: primeiramente um gato apresentando resultado positivo para a retrovirose, deve ser diagnosticado como tendo a infecção, mas não necessariamente a doença que este animal está apresentando é decorrente dessa infecção. Em segundo lugar, a decisão da eutanásia não deve ser feita apenas levando em consideração um resultado positivo, pois um gato infectado pode viver por muitos anos. Por fim, nenhum teste de diagnóstico é sempre $100 \%$ preciso, por tanto, o ideal é confirmar os resultados que se apresentarem positivos com outros testes (Levy et al., 2008).

É de extrema importância o diagnóstico correto das infecções por retrovírus para os animais infectados e também para aqueles não infectados, visto que uma falha no diagnóstico de um gato positivo pode levar à disseminação da doença para animais sadios. Além disso, o diagnóstico incorreto pode resultar em um tratamento incorreto, e comprometendo assim a saúde do animal (Levy et al., 2008).

É comum encontrar no hemograma de gatos positivos anemia arregenerativa com ou sem trombocitopenia, linfopenia ou neutropenia, devido à supressão da medula óssea ou destruição imunomediada; também é frequente a presença de hemácias nucleadas em esfregaço, ou macrocitose sem reticulocitose (Norsworthy, 2004. A presença dessas hemácias nucleadas não é certeza de uma anemia regenerativa, podendo ser resultado de um distúrbio medular não específico, sendo então necessária uma contagem de reticulócitos para tal determinação. No perfil bioquímico pode-se encontrar aumento das enzimas hepáticas e bilirrubina (Norsworthy, 2004).

No exame da medula óssea não é incomum observar a interrupção da maturação dos eritrócitos, pois o vírus também pode induzir a destruição imunomediada dessas células, bem como a infecção secundária por $M$. haemofelis, devendo então diferenciar a causa dessa reação auto-imune. Alguns felinos com o FeLV podem apresentar sinais gastrointestinais e neutropenia, podendo ser confundido com a panleucopenia felina, sendo então diferenciados desta por apresentarem anemia e trombocitopenia na infecção pelo FeLV, enquanto que na panleucopenia tais alterações laboratoriais são raros. Nos exames bioquímicos é comum apresentar hiperbilirrubinemia, aumento da atividade das enzimas hepáticas, azotemia. Gatos com linfoma podem apresentar alterações radiográficas, sendo estas dependentes do local acometido. Alguns animais apresentam derrame pleural, ao qual a análise do líquido é normal apresentar linfoblastos, alta contagem de células totais e alto teor protéico (Norsworthy, 2004).

$\mathrm{O}$ método usado rotineiramente para diagnóstico laboratorial é a detecção sérica do antígeno viral p27 (Barr, 1996), e para diagnóstico confirmatório o isolamento viral (Quinn et al., 2005). O ELISA é a principal técnica utilizada para detectar o antígeno p27 em sangue total, saliva, lágrimas, soro ou plasma; estando presente em maior quantidade no plasma de animais infectados (Levy et al., 2008; Norsworthy, 2009). O soro é o meio que gera menos resultados falso-positivos e falsonegativos quando comparado com outros materiais, por isso é o meio de preferência para a realização dos exames (Mehl, 2004). Não é recomendado o uso de testes que usam lágrimas ou saliva, pois apresentam resultados muito imprecisos (Levy et al., 2008). 
O teste ELISA é o teste disponível em kits comerciais para detecção do referido antígeno, e normalmente esses testes de triagem passam a reagir, a partir de 30 dias depois da infecção pelo vírus. Entretanto, o desenvolvimento da antigenemia pode variar entre os animais, podendo até ser demorada em alguns gatos. Quando resultados para detecção do antígeno são negativos, mas não se pode descartar uma possível exposição ao vírus, deve-se repetir o teste após 30 dias, ou realizar PCR para detecção de provírus (Levy et al., 2008). Pelo fato dos anticorpos maternos contra o agente em questão não interferirem nos resultados de testes de diagnóstico para antígeno, os filhotes podem ser testados em qualquer fase. Mas pode ocorrer de apresentarem resultados negativos durante semanas a meses após a infecção resultante de transmissão materna e depois desse tempo, quando o vírus iniciar a replicação, os resultados acabam por se tornarem positivos (Hartmann, 2006).

No Brasil, os kits comerciais licenciados pelo Ministério da Agricultura, Pecuária e Abastecimento são Anigen Rapid FIV/FeLV Test Bioeasy, da Bioeasy Diagnótica LTDA e o SNAP FeLV, da REM Indústria e Comércio (MAPA, 2014).

O IFI, assim como o ELISA, tem como base a detecção do antígeno p27, porém, sua detecção é em neutrófilos e plaquetas infectados (Norsworthy et al., 2004, Meinerz et al., 2010) obtidos de esfregaços sanguíneos ou de medula óssea (Levy et al., 2008). E se torna positivo a partir do momento em que a infecção atinge a medula óssea, indicando que o animal está infectado e virêmico (Levy et al., 2008, Meinerz et al., 2010). Podem ocorrer resultados falsonegativos em casos de linfopenia ou trombopenia, pois um número não adequado de células poderia impedir a avaliação (Levy et al., 2008, Meinerz et al., 2010). Outros resultados falso-negativos podem ser decorrentes de infecções regressivas ou em gatos que conseguiram impedir que a infecção atingisse a medula óssea. Resultados falsos positivos podem ocorrer por erros laboratoriais (Levy et al., 2008).

A detecção no soro, por meio do ELISA é possível antes da infecção atingir a medula óssea, dessa forma, tal detecção não significa necessariamente que a infecção virá a se tornar persistente, ou que o gato é contagioso, pois pode determinar resultados positivos para aqueles animais que apresentam a doença em sua forma autolimitante ou em sua fase inicial, enquanto, exames de IFI nesses casos poderiam ser negativos (Norsworthy et al., 2004, Levy et al., 2008). Animais apresentando este tipo de resultado devem ser isolados, apesar de provavelmente não serem contagiosos durante essa fase, devendo repetir o exame após quatro a seis semanas, na qual a doença poderá progredir para uma infecção persistente. Caso os exames de ELISA e IFI nesses gatos tornem a apresentar resultados discordantes, os testes podem continuar sendo feitos anualmente, ou até que os resultados sejam os mesmos (Levy et al., 2008). Um resultado negativo no teste ELISA e positivo no teste IFI é improvável, e caso aconteça, é possível que seja erro de técnica.

Há três motivos para um resultado negativo no teste ELISA: (i) o animal pode não estar infectado, pois não houve exposição ao vírus, ou por ter ocorrido à eliminação da infecção devido à produção de anticorpos; (ii) pode estar ocorrendo uma infecção hiperaguda; (iii) ou o felino pode ter eliminado o vírus do soro e estar em uma infecção latente (Mehl, 2004). Resultado negativo em kits comerciais pode indicar uma infecção regressiva, mas para ter certeza deve-se fazer o exame de PCR para detecção de provírus, visto que em várias pesquisas $5-10 \%$ dos animais que participaram apresentaram resultados negativos no teste de antígeno solúvel e positivo no PCR. Ainda sim, o significado clínico de um animal que apresentou resultado negativo para antígeno viral e positivo para pró-vírus é desconhecido, mas aparentemente eles não desenvolvem viremia, não secretam o vírus, e é improvável que desenvolvam doenças relacionadas (Levy et al., 2008).

O valor preditivo positivo desses testes comerciais é menor que $90 \%$, considerado baixo, sendo o valor dos testes Witness FeLV da SynBiotics Corporation e Combo SNAP FeLV/FIV da IDEXX Laboratories, os dois kits mais usados, são de apenas $74 \%$; por isso um resultado positivo deve ser confirmado com outros testes. Para confirmação pode ser feito novamente um teste rápido, porém de outra marca, ou o teste IFI para detecção da proteína 
p27 em leucócitos e plaquetas após a infecção atingir a medula óssea, o que confirmaria um gato persistentemente infectado.

O PCR é um teste sensível e quando feito de forma adequada pode ser um bom aliado para confirmação do diagnóstico da leucemia viral felina, principalmente quando há resultados discordantes entre o ELISA e o IFI ou quando há suspeita da doença, mas não foram detectados antígenos. Dependendo de como é feito, pode detectar RNA viral ou pró-vírus. Os materiais para realização do PCR podem ser aspirados de medula óssea e tecidos, e o sangue (Levy et al., 2008).

O isolamento viral é uma técnica muito usada para o diagnóstico do FeLV (Ramsey, 2010). Ele identifica replicações virais capazes de serem infecciosas e normalmente seus resultados condizem com os obtidos em testes de triagem, os quais detectam antígeno circulante, dessa forma o isolamento viral pode ser escolhido para confirmação.

Um aspirado de medula óssea pode revelar se há anormalidades medulares, mesmo quando o hemograma parece normal; além disso, o aspirado é uma boa amostra para a realização do teste IFI, visto que em alguns gatos o vírus pode ser encontrado na medula, mesmo tendo apresentado resultado negativo em testes que detectam o antígeno no soro (Norsworthy et al., 2004).

A vacinação não interfere nos resultados de nenhum dos testes mencionados, visto que os mesmos têm como base a detecção de antígenos ou DNA virais e não anticorpos produzidos pelo animal. Apesar disso, o ideal é testar os gatos antes de serem vacinados, pois pode haver quantidades de RNA e antígenos de cepas virais oriundas da vacina que podem atingir níveis detectáveis caso o teste seja feito logo após a vacinação. Ainda não se sabe por quanto tempo pode haver interferência da vacinação (Levy et al., 2008 .

Os animais que devem ser testados em busca do FeLV são todos aqueles com acesso à rua ou de origens desconhecidas, além daqueles que apresentam sinais clínicos da doença em questão, como forma de diagnóstico. Como a vacina não proporciona uma proteção completa, gatos vacinados também devem ser testados anualmente. Se houve exposição, os felinos devem ser testados quatro a oito semanas após o suposto contato com o vírus, e novamente após 12 semanas. Como o resultado do ELISA não é influenciado por anticorpos maternos, os filhotes também podem ser testados, o que deve ser feito antes dos mesmos terem contato com outros felinos da casa (Mehl, 2004).

\section{Tratamento}

Muitos proprietários ficam assustados ao receberem o diagnóstico positivo de seus gatos, assim, é importante acalmá-los e aconselhá-los sobre o tratamento adequado. Alguns pontos devem ser frisados, como a importância da manutenção desses felinos dentro de casa para que não haja risco de adquirirem infecções oportunistas e também para que não sirvam como fonte de infecção para outros gatos. Caso haja outros gatos na casa, o proprietário deve isolar em um quarto o felino infectado (Levy et al., 2008).

É importante que exames de rotina devam ser feitos pelo menos duas vezes por ano nos gatos infectados. Deve-se sempre estar atento ao histórico desses animais, incluindo qualquer sinal de perda de peso. Ao exame clínico devem-se examinar olhos, cavidade oral e linfonodos. Exames de perfil bioquímico e hemograma completo também devem ser feitos. A maioria dos gatos infectados desenvolve uma resposta imune adequada às vacinas de rotina, assim essas devem continuar sendo feitas. Animais não castrados podem e devem ser castrados, se estiverem clinicamente estáveis para serem submetidos à cirurgia (Levy et al., 2008).

Como tratamento da doença, drogas antivirais têm sido propostas, como a zidovudina ou azidotimidina (AZT) que é uma inibidora da transcriptase reversa, seu uso tem sido muito estudado, porém a administração em felinos persistentemente virêmicos não tem eliminado a viremia Além disso, sua administração tem mostrado resultados mais efetivos em gatos experimentalmente infectados, que em gatos infectados naturalmente (Hartmann, 2006). A disponibilidade das drogas antivirais é limitada, e apresenta muitos efeitos tóxicos (Levy et al., 2008). A dose da AZT é de $5-10 \mathrm{mg} / \mathrm{Kg}$, VO (via 
oral) ou SC (via subcutânea) a cada doze horas (Hartmann, 2006, Hartmann, 2005, Mehl, 2004). A maior dosagem deve ser usada com cautela, visto que há efeitos colaterais como o desenvolvimento de anemia arregenerativa (Hartmann, 2005). Caso usado de forma SC, o medicamento deve ser diluído em solução de cloreto de sódio $0,9 \%$, para reduzir possíveis irritações locais. Para as administrações de forma oral, há xaropes com sabor de framboesa, ou cápsulas. Outras drogas antivirais que são comumente usadas no tratamento do HIV em humanos, e que o uso em felinos ainda está sendo estudado, são: Didanosina, Zalcitabina, Ribavirina, Suramin e Foscarnet (Hartmann, 2006).

Pode ter melhora dos sinais clínicos em alguns casos utilizando-se a imunoterapia, com drogas como proteína A do Staphylococcus spp., Proprionibacterium acnes, acermannan, ou interferon- $\alpha$ humano (Mehl, 2004). A administração de $30 \mathrm{UI} / g a t o$ de interferon- $\alpha$, usado para promover a resposta imune do animal infectado, VO a cada 24 horas tem resultado em melhora clínica de alguns felinos (Mehl, 2004).

Em gatos que desenvolveram neoplasias deve ser feito tratamento com combinações de drogas quimioterápicas, para ter uma melhor chance de remissão completa. É comum a combinação de doxorrubicina com vincristina, prednisona e ciclofosfamida (Hartmann, 2006).

Para aqueles com doenças oportunistas, seus agentes devem ser controlados usando tratamentos específicos. Quanto a tratamentos suportes para casos em que há anemia arregenerativa como, vitamina B12, ácido fólico e eritropoetina normalmente não são bem sucedidos, mas pode responder à transfusões sanguíneas (Mehl, 2004).

Anemias hemolíticas causadas por $M$. haemofelis respondem bem ao tratamento com doxiciclina (Mehl, 2004; Hartmann, 2006). A transfusão sanguínea pode ser necessária em casos de anemias arregenerativas, para estabilização do paciente. Quando há anemia hemolítica, pode ser usado o corticóide prednisona, mas apenas nos casos em que há certeza que a anemia é por reação imunomediada (Hartmann, 2006).
O tratamento do FeLV não resulta em cura, apenas em remissão, uma vez que o vírus permanece viável no organismo, desta forma há possibilidade de contágio e podem ocorrer remissões (Norsworthy et al., 2004)). O prognóstico é reservado em casos de viremia persistente (Norsworthy et al., 2004), mas a expectativa média de vida é de dois anos (Mehl, 2004. Felinos infectados, mas que não apresentam sinais clínicos pode permanecer meses ou até anos assintomáticos (Norsworthy et al., 2004).

\section{Prevenção}

Para maximizar a prevenção da leucemia viral felina podem ser feitas parcerias entre os proprietários e os médicos veterinários. Educação de pessoal, a realização de testes de diagnóstico, vacinações e disponibilizar maiores informações sobre a infecção para os proprietários são algumas das ações que podem fazer com que a disseminação da doença diminua (Levy et al., 2008).

Evitar o contado do felino com o vírus por meio do não compartilhamento dos comedouros e bebedouros entre os gatos infectados e os não infectados, mantê-los sem acesso à rua, e o isolamento dos animais soropositivos, são as melhores formas de prevenção da doença. Apesar de a eficácia da vacina ainda ser questionada, seu uso deve ser considerado em gatos que ainda não foram expostos ao FeLV.

A vacina ideal deve induzir a produção de anticorpos contra o subgrupo A, mas nenhuma das disponíveis ocasiona isso. Todas proporcionam certa proteção contra a infecção, mas não se sabe qual fornece melhor proteção, pois não há consenso entre os protocolos utilizados. A eficácia dos diferentes tipos de vacina em induzir uma resposta imune adequada contra a infecção persistente varia consideravelmente (Sparkes, 1997; Quinn et al., 2005; Ramsey, 2010), pois o modo como são produzidas é diferente e usam diferentes antígenos e adjuvantes. Estudos indicam que a imunidade induzida pela vacina persiste em torno de 12 meses, mas ninguém sabe ao certo a real duração, e esse tempo pode até ser maior (Levy et al., 2008).

Há cinco vacinas disponíveis comercialmente 
nos Estados Unidos e Europa, sendo que todas possuem o vírus inativo, mas diferem em outras características: das cinco, três contêm o vírus de forma inteira e duas em subunidades (sendo uma delas recombinante); quatro possuem adjuvante; e por fim elas apresentam subgrupos diferentes do vírus (Sparkes, 1997). Como nenhuma vacina tem $100 \%$ de eficácia, a mesma não exclui a importância de testar os animais para identificar e separar os infectados, além disso, a determinação para a vacinação de um felino deve ser baseada avaliando-se o risco de exposição ao vírus que o animal apresenta (Levy et al., 2008).

A vacinação é recomendada àqueles felinos que têm acesso à rua, ou que vivem em locais com muitos gatos (como exemplo abrigos), naqueles que tem contato direto com outros gatos dos quais não se tem conhecimento sobre se são ou não infectados, ou ainda em felinos que convivem com outros gatos positivos. Ou seja, é recomendada para gatos que apresentam risco de exposição ao vírus (Mehl, 2004; Levy et al.,
2008; Norsworthy, 2009). Também é aconselhada em filhotes, pois seus estilos de vida mudam após a aquisição, e futuramente podem acabar sendo expostos ao vírus (Levy et al., 2008). A American Association of Feline Practitioner's (AAFP) aconselha também o reforço anual e afirma que a vacinação deve ser feita no membro posterior esquerdo, devido ao risco do desenvolvimento de sarcomas vacinais (Mehl, 2004). Além disso, sugere que os gatos sejam testados antes de serem vacinados contra o FeLV, quando doentes, assim que forem adquiridos, ou ainda antes de terem uma possível exposição ao vírus.

Quando a vacinação é necessária recomenda-se a aplicação de duas doses, sendo a primeira feita com oito semanas de idade, e a segunda realizada três a quatro semanas depois. Caso o gato continue apresentando risco de exposição, o reforço da vacina só deve ser feito anualmente (Levy et al., 2008).

\begin{tabular}{|c|c|c|c|c|}
\hline Nome comercial & Fabricante & $\begin{array}{l}\text { Tipo de } \\
\text { antígeno }\end{array}$ & $\begin{array}{c}\text { Via de } \\
\text { administração }\end{array}$ & $\begin{array}{c}\text { Idade } \\
\text { recomendada }\end{array}$ \\
\hline Feligen® FeLV & $\begin{array}{l}\text { Virbac do } \\
\text { Brasil } \\
\text { Indústria e } \\
\text { Comércio } \\
\text { LTDA }\end{array}$ & $\begin{array}{l}\text { Molécula } \\
\text { recombinante do } \\
\text { antígeno p45 }\end{array}$ & $\mathrm{SC}^{*}$ & $\begin{array}{c}8 \text { a } 9 \text { semanas. } \\
\text { Repetir dose } 3 \text { a } 4 \\
\text { semanas depois }\end{array}$ \\
\hline $\begin{array}{l}\text { Fel-O-Guard® } \\
\text { Plus 4+LvK }\end{array}$ & $\begin{array}{c}\text { Fort Dodge } \\
\text { Saúde Animal } \\
\text { LTDA }\end{array}$ & Vírus inativo & $\mathrm{SC}$ & $\begin{array}{c}8 \text { semanas ou mais } \\
\text { velhos. Repetir dose } 3 \\
\text { a } 4 \text { semanas depois }\end{array}$ \\
\hline $\begin{array}{c}\text { Fel-O-Vax LvK } \\
\text { IV } ®\end{array}$ & $\begin{array}{c}\text { Fort Dodge } \\
\text { Saúde Animal } \\
\text { LTDA }\end{array}$ & Vírus inativo & $\mathrm{SC}$ & $\begin{array}{c}8 \text { a } 10 \text { semanas ou } \\
\text { mais velhos. Repetir } \\
\text { dose } 3 \text { a } 4 \text { semanas } \\
\text { depois }\end{array}$ \\
\hline $\begin{array}{l}\text { Fel-O-Vax LvK } \\
\text { IV® + Calicivax }\end{array}$ & $\begin{array}{c}\text { Fort Dodge } \\
\text { Saúde Animal } \\
\text { LTDA }\end{array}$ & Vírus inativo & $\mathrm{SC}$ & $\begin{array}{c}8 \text { semanas ou mais } \\
\text { velhos. Repetir dose } 3 \\
\text { a } 4 \text { semanas depois }\end{array}$ \\
\hline $\begin{array}{l}\text { QUANTUM® } \\
\text { FELIS } 4+\text { FeLV }\end{array}$ & $\begin{array}{c}\text { Coopers } \\
\text { Saúde Animal } \\
\text { Indústria e } \\
\text { Comércio } \\
\text { LTDA }\end{array}$ & - & $\mathrm{SC}$ ou IM** & $\begin{array}{l}\text { Mais de } 9 \text { semanas. } \\
\text { Repetir dose } 3 \text { a } 4 \\
\text { semanas depois }\end{array}$ \\
\hline
\end{tabular}

Quadro 1- Vacinas para leucemia viral felina licenciadas para uso no Brasil, de acordo com o Ministério da Agricultura, Pecuária e Abastecimento (MAPA), 2014. *SC: via de administração subcutânea. **IM: via de administração intramuscular 
Algumas reações adversas à vacinação incluem: febre, letargia, dor e inchaço local. E essas reações adversas mais leves devido ao uso das vacinas são pouco relatadas, mas o que realmente é observado ao fazer um acompanhamento desses animais vacinados é o oposto. Ou seja, a incidência dessas reações são maiores do que o que realmente é relatado pelos fabricantes. Uma reação adversa mais grave que tem sido relatada e associada às vacinações repetidas, especialmente quando apresentam adjuvantes, é o desenvolvimento de sarcoma no local da aplicação (Sparkes, 1997).

O teste para diagnóstico é altamente recomendado para aqueles que vivem em ambientes com muitos gatos, e pessoas que adotam muitos felinos devem testar seus próprios animais, antes de acolherem um novo membro. Como alguns animais podem ter uma infecção regressiva, apresentando assim resultado negativo no teste ELISA, mas ainda sim possuir pró-vírus em seu organismo os quais podem ser transmitidos através do sangue e serem infecciosos para outro gato, doadores de sangue sempre deve ser testados. Nesse caso para o teste recomenda-se o PCR, o qual vai detectar os próvírus (Levy et al., 2008).

Para aqueles soropositivos, o ideal é mantê-los sem acesso à rua a fim de evitar que ocorram infecções oportunistas (Mehl, 2004).

A detecção prévia de gatos infectados é de extrema importância, visto que essa ação ajudaria na introdução de práticas de controle da disseminação da doença, além de proporcionar uma melhora nos cuidados ao animal doente (Levy et al., 2008).

Um método de baixo custo e de fácil aplicação para o controle da disseminação da doença é o esquema de teste e remoção. Esse consiste em identificar os animais positivos do domicílio e separá-los dos animais não infectados; sendo que os gatos que apresentarem resultado positivo em um primeiro teste devem ser testados novamente após 12 semanas para confirmação, visto que alguns felinos podem se recuperar da infecção.

Como o vírus não resiste no meio ambiente, a separação dos animais infectados e sadios pode ser apenas física, como mantê-los em quartos separados (Quinn et al., 2005; Levy et al., 2008; Ramsey, 2010).

Para limitar a transmissão no ambiente de clínicas veterinárias, a simples higienização com desinfetantes ou detergentes é suficiente. As pessoas que trabalham na clínica devem sempre lavar as mãos após terem contato com um gato infectado. Com relação ao manejo desses animais nas clínicas, quando internados devem ficar em gaiolas individuais e não em locais onde possam ser expostos a agentes contagiosos (Levy et al., 2008).

Para os criadores de gatos: é necessária uma vigilância contínua para prevenir a entrada da retrovirose no gatil. As características de gatis fazem com que a disseminação da leucemia viral felina nesse ambiente seja facilitada. Como exemplo, a prática de enviar fêmeas para outros gatis para reprodução, a introdução de novos gatos, o convívio em grupo dos felinos e a mistura de animais mais jovens com mais velhos. Quando o teste para diagnóstico é feito pela primeira vez, todos os animais devem apresentar resultado negativo em dois testes, sendo o segundo realizado 60 dias após o primeiro (Levy et al., 2008).

Com relação à saúde pública, até o momento nenhum estudo comprovou risco à saúde humana (Mehl, 2004; Norsworthy, 2009).

\section{Considerações finais}

A leucemia viral felina é uma doença comum entre os gatos domésticos, mas pouco lembrada nas clínicas veterinárias ao considerar os diagnósticos diferenciais. Sua forma de transmissão é pelo simples contado entre os gatos. A principal forma de prevenção dessa doença é impedindo o contato entre gatos infectados e gatos não infectados, além de impedir o acesso à rua.

A doença abordada no presente trabalho tem relevância clínica, bem como seu diagnóstico e correto tratamento. Dessa forma, maiores estudos sobre a mesma podem contribuir no diagnóstico diferencial de outras doenças que acometem os felinos. 


\section{Referências Bibliográfuicas}

Almeida, N. R. 2009. Ocorrência da infecção pelo vírus da laucemia felina (FeLV) em gatos domésticos do município do Rio de Janeiro e baixada fluminense e análise dos fatores de risco para a infecção. Veterinária. Universidade Federal do Rio de Janeiro, Rio de Janeiro.

Arjona, A.; Escolar, E.; Soto, I.; Barquero, N.; Martin, D. \& Gomez-Lucia, E. 2000. Seroepidemiological survey of infection by feline leukemia virus and immunodeficiency virus in Madrid and correlation with some clinical aspects. Journal of Clinical Microbiology, 38, 3448-3449.

Barr, M. C. 1996. FIV, FeLV, and FIPV: interpretation and misinterpretation of serological test results. Seminars in veterinary medicine and surgery (small animal).

Chhetri, B. K.; Berke, O.; Pearl, D. L. \& Bienzle, D. 2013. Comparison of the geographical distribution of feline immunodeficiency virus and feline leukemia virus infections in the United States of America (2000-2011). BMC Veterinary Research, 9, 2.

Figueiredo, A. S. \& Araújo Júnior, J. P. 2011. Vírus da leucemia felina: análise da classificação da infecção, das técnicas de diagnóstico e da eficácia da vacinação com o emprego de técnicas sensíveis de detecção viral. Ciência Rural, 41, 1952-1959.

Hardy, W. D.; McClelland, A.; Zuckerman, E. E.; Hess, P. W.; Essex, M.; Cotter, S. M.; MacEwen, E. G. \& Hayes, A. A. 1976. Prevention of the contagious spread of feline leukaemia virus and the development of leukaemia in pet cats. Nature, 263, 326-328.

Hartmann, K. 2005. FeLV treatment strategies and prognosis. Compendium on continuing education for the practicing veterinarian, 27, 14-26.

Hartmann, K. 2006. Infectious diseases of the dog and cat, 3ed edn. Elsevier Health Sciences, Canadá.

Hayes, K. A.; Rojko, J. L.; Tarr, M. J.; Polas, P. J.; Olsen, R. G. \& Mathes, L. E. 1989. Atypical localised viral expression in a cat with feline leukaemia. Veterinary Record, 124, 344-346.

Hofmann-Lehmann, R.; Huder, J. B.; Gruber, S.; Boretti, F.; Sigrist, B. \& Lutz, H. 2001. Feline leukaemia provirus load during the course of experimental infection and in naturally infected cats. Journal of General Virology, $82,1589-1596$.

Hoover, E. A. \& Mullins, J. I. 1991. Feline leukemia virus infection and diseases. Journal of the American Veterinary Medical Association, 199, 1287-1297.

Jarrett, W. F.; Crawford, E. M.; Martin, W. B. \& Davie, F. 1964. A virus-like particle associated with leukemia (lymphosarcoma). Nature, 202, 567-569.

Levy, J.; Crawford, C.; Hartmann, K.; HofmannLehmann, R.; Little, S.; Sundahl, E. \& Thayer, V. 2008. American Association of Feline Practitioners' feline retrovirus management guidelines. Journal of Feline Medicine and Surgery, 10, 300-316.

Levy, J. K.; Scott, H. M.; Lachtara, J. L. \& Crawford, P. C. 2006. Seroprevalence of feline leukemia virus and feline immunodeficiency virus infection among cats in North America and risk factors for seropositivity. Journal of the American Veterinary Medical Association, 228, 371376.

MAPA. 2014. Instrução Normativa $n^{\circ} 62$ de 31/12/2011. Ministério da Agricultura, Pecuária e Abastecimento.

Marker, L.; Munson, L.; Basson, P. A. \& Quackenbush, S. 2003. Multicentric T-cell lymphoma associated with feline leukemia virus infection in a captive Namibian cheetah (Acinonyx jubatus). Journal of Wildlife Diseases, 39, 690-695.

Mehl, M. L. 2004. Segredos em medicina interna de felinos: respostas necessárias ao dia-a-dia em rounds, na clínica, em exames orais e escritos. ARTMED.

Meinerz, A. R. M.; Ávila Antunes, T.; Souza, L. L.; Silva Nascente, P.; de Faria, R. O.; Cleff, M. B.; Gomes, F. R.; Oliveira Nobre, M.; Reischak, D. \& Schuch, L. F. D. 2010. Frequência do virus da leucemia felina 
(VLFe) em felinos domésticos (Felis catus) semidomiciliados nos municípios de Pelotas e Rio Grande. Ciência Animal Brasileira, 11, 90-93.

Norsworthy, G. D.; Crystal, M. A.; Grace, S. F. \& Tilley, L. P. 2004. O paciente felino. São Paulo: Roca, 3, 300.

Ostrowski, S.; Van Vuuren, M.; Lenain, D. M. \& Durand, A. 2003. A serologic survey of wild felids from central west Saudi Arabia. Journal of Wildlife Diseases, 39, 696-701.

Quinn, P. J.; Markey, B. K.; Carter, M. E.; Donnelly, W. J. \& Leonard, F. C. 2005. Microbiologia veterinária e doenças infecciosas. Artmed, Porto Alegre.

Ramsey, I. K. \& Tennant, J. R. B. 2010. Manual de doenças infecciosas em cães e gatos. São Paulo: Roca.

Sleeman, J. M.; Keane, J. M.; Johnson, J. S.; Brown, R. J. \& Woude, S. V. 2001. Feline leukemia virus in a captive bobcat. Journal of Wildlife Diseases, 37, 194-200.

Sparkes, A. H. 1997. Feline leukaemia virus: a review of immunity and vaccination. Journal of Small Animal Practice, 38, 187-194.

Teixeira, B. M.; Rajão, D. S.; Haddad, J. P.; Leite, R. C. \& Reis, J. K. 2007. Ocorrência do vírus da imunodeficiência felina e do vírus da leucemia felina em gatos domésticos mantidos em abrigos no município de Belo Horizonte. Arquivo Brasileiro de Medicina Veterinária e Zootecnia, 59, 939-942.

Recebido em Agosto 18, 2014.

Aceito em Novembro 04, 2014.

License information: This is an open-access article distributed under the terms of the Creative Commons Attribution License, which permits unrestricted use, distribution, and reproduction in any medium, provided the original work is properly cited. 